\title{
Effect of salinity on growth, survival and biochemical alterations in the freshwater fish Labeo rohita (Hamilton 1822)
}

\author{
KAMAL SARMA ${ }^{1}$, A. DEY ${ }^{1}$, SANTOSH KUMAR ${ }^{1}$, B. K. CHAUDHARY ${ }^{2}$, S. MOHANTY ${ }^{3}$, \\ TARAKESHWAR KUMAR ${ }^{1}$, S. S. PRASAD ${ }^{4}$ AND B. P. BHATT ${ }^{1}$ \\ ${ }^{1}$ ICAR-Research Complex for Eastern Region, Patna - 800 014, Bihar, India \\ ${ }^{2}$ ICAR-National Institute of Biotic Stress Management, Baronda, Raipur - 493 225, Chhattishgarh, India \\ ${ }^{3}$ ICAR-Central Institute of Freshwater Aquaculture, Bhubaneswar - 751 002, Odisha, India \\ ${ }^{4}$ Department of Soil Science, Rajendra Agricultural University, Pusa - 848 125, Bihar, India \\ e-mail:tarkeshwariac@gmail.com
}

\begin{abstract}
Salinity tolerance in Labeo rohita (Hamilton 1822) fingerling was conducted for $96 \mathrm{~h}$ using a static, non-renewal system and $\mathrm{LC}_{50}$ determined for 48 and $96 \mathrm{~h}$ exposure were 9.60 and 7.72\%o with standard deviation 9.27-9.93 and 7.41-8.03\%, respectively. For sublethal study, 0, 2.5, 3.5 and 4.5\% were selected to assess the chronic effect of salinity on this species. At the end of 90 days of exposure, it was found that the average weight gain was maximum at $0 \%$ followed by $2.5 \%$, then $3.5 \%$ and the least at $4.5 \%$. Similarly, highest mortality $(43.75 \%)$ was recorded in fishes exposed to $4.5 \%$ salinity and least $(12.5 \%)$ at $2.5 \%$ at the end of 90 days of experiment. On termination of the experiment, ascorbic acid level was found significantly reduced $(\mathrm{p}<0.05)$ in brain, liver and muscle tissues in fishes exposed to salinity stress. Oxygen consumption rate of fish was maximum at $2.5 \%$ salinity which gradually decreased with increase in salinity and the lowest was observed at $4.5 \%$. From results of the study, it can be concluded that with increase in salinity, the survival rate, growth and tissue ascorbic acid level in L. rohita decreases. These results clearly indicated that $L$. rohita is vulnerable when exposed to higher salinity for longer duration.
\end{abstract}

Keywords: Ascorbic acid, Labeo rohita, Oxygen consumption, Salinity tolerance

\section{Introduction}

Salt affected soils are important ecological entity occupying $6 \%$ of the global land area and $2.6 \%$ of the geographical area in India. Indo-Gangetic Plain (IGP), which is the most fertile agricultural region in India also has around 3.095 million ha land is salt affected areas of which 12\% exist in Bihar (Mandal and Sharma, 2006). Utilisation of these salt affected areas for productive purpose is the major challenge for the region. In this regard, inland saline aquaculture provides an opportunity for the diversification and expansion of agriculture through a potentially productive use of land that can no longer support standard agricultural enterprises (McDowall et al., 2016). Thus, aquaculture can be an adaptive approach to this environmental problem and can represent a potentially lucrative use for salt-affected land, with many economic, social and environmental benefits (Lymbery et al., 2007). However, selection of suitable fish species having tolerance to saline conditions is very important before venturing into aquaculture in these areas. This is mainly because higher salinity of water can act as an important stressor under natural as well as aquaculture conditions (Islam et al., 2014) and can directly influence the metabolism of fish, which ultimately affects the survival, growth, feed intake and even distribution of species (Garg, 1996; Sahoo et al., 2003; Kang'ombe and Brown, 2008; Akhtar et al., 2013; Mubarik et al., 2015).

Effects of salinity have been studied in several fish species but detailed work on effect of salinity on growth, survival and biochemical response on freshwater fish species are limited. Labeo rohita (Hamilton 1822), commonly known as 'rohu', is one of the Indian major carps (IMCs) used successfully in commercial aquaculture in the Indian subcontinent at least for the past six decades (Sahoo et al., 2015). It is considered to be a highly delicious fish species, has high market value and the fry and fingerlings of the species are easily available from freshwater finfish hatcheries across the country. Hence, a detailed study on the physiological responses and tolerance limit of this species to various salinity levels and an understanding on the potentiality of this species for culture in low saline waters could be highly beneficial. Therefore, the present study was undertaken with an objective to investigate the effects of shortterm as well as long-term exposure of the species to various salinity levels on growth, survival and selected biochemical parameters of rohu fingerlings under laboratory conditions. 


\section{Materials and methods}

\section{Experimental fish}

Healthy fingerlings of L. rohita $(14.93 \pm 0.39 \mathrm{~cm}$ and $23.1 \pm 1.86 \mathrm{~g}$ ) were collected from the freshwater fish seed rearing farm of the ICAR-Research Complex for Eastern Region, Patna, Bihar. The fish were acclimatised to the laboratory conditions for a period of 15 days separately prior to the experimental trials.

\section{Salinity tolerance trial}

A static non-renewable salinity tolerance bioassay was conducted following standard methods (Reish and Oshida, 1987; APHA, 1998) to determine LC $_{50}$ of salinity for rohu fingerlings for $96 \mathrm{~h}$. Brine solution was prepared using common raw salt and was used for preparing water with desired salinity (treatment) for the experiment. Initially a range finding test was conducted and based on the results, definitive test was conducted using 7 treatments, starting from $2 \%$ to $14 \%$ o concentration (Table 1). The test was conducted in triplicates comprising 10 fishes each in 301 test solution. In each tank, required volume of brine was added and thoroughly mixed and allowed to stand to $20 \mathrm{~min}$ before introduction of fishes. Simultaneously one control was also kept slightly away from the bioassay tanks to avoid contamination. No feeding was done and static nonrenewable method was followed. Round the clock aeration was provided in all the tanks using a portable aerator. Just before release of the fishes in the test solution, temperature, $\mathrm{pH}$, dissolved oxygen and actual salinity were estimated (HANNA Multiparameter Analyser, HI 9829, Germany) from all the treatments and the parameters were found to be within the acceptable limits. Percentage mortality was recorded at 24, 48, 72 and $96 \mathrm{~h}$ intervals. Dead fishes were immediately removed from respective tanks. The data obtained from the experiment was subjected to probit analysis to estimate $96 \mathrm{~h} \mathrm{LC}_{50}$.

Based on the $96 \mathrm{~h} \mathrm{LC}_{50}$ value estimated for $L$. rohita fingerlings, three different sub-lethal salinities viz., $2.5,3.5$ and $4.5 \%$ and a control $(0 \%$ ) were selected to assess the effect of salinity on the fishes. Water quality parameters were maintained at optimum levels throughout the experimental period. For preparation of water of required salinity, similar procedure as mentioned earlier was followed. Freshwater $(0.22 \%)$ was collected from a nearby bore well and stored in separate tanks (500 1) at least 3 days prior to use for preparation of brine and test solutions. For the experiment, 401 of water was maintained in the experimental tanks throughout the experiment. Completely randomised design was followed and 64 fish were distributed in four different groups with two replicates per treatment. Feeding was done at the rate of 3\% body weight per day. Standard pelleted feed with protein level $16.52 \pm 0.46 \%$ was used for feeding fishes. Uneaten food and faecal matter were removed on daily basis and complete water exchange was done once in a week and the study was conducted for a period of 90 days.

Monthly sampling was carried out to ascertain weight gain and survival of the fish using the following formulae:

Weight gain $(\%)=\frac{\text { Final weight-Initial weight }}{\text { Initial weight }} \times 100$

Survival $(\%)=\frac{\text { Number of fish survived after } 90 \text { days }}{\text { Initial number of fish stocked }} \times 100$

At the end of 90 days of experimental period, 6 fish per treatment ( 3 per tank) were sampled, anaesthetised with clove oil $\left(50 \mu \mathrm{l} \mathrm{l}^{-1}\right)$ and tissue samples were collected from different organs for ascorbic acid analysis. For estimation, fresh tissues (kidney, brain and muscle) were used on wet weight basis. Ascorbic acid content was determined using 2, 4-dinitro-phenylhydrazine (DNPH) method following Roe and Keuther (1943). OD was measured in a UV-VIS spectrophotometer (E-Merck, Germany) at $540 \mathrm{~nm}$.

Oxygen consumption rate (Debnath et al., 2006) of fishes was estimated after 60 days of salinity exposure. The study was carried out after $96 \mathrm{~h}$ of weekly water exchange. Three fishes from each concentration were sampled after 24, 48, 72 and $96 \mathrm{~h}$ of salinity exposure and kept individually in a sealed glass chamber (2 1) having thick glass lid covering the top portion completely. After taking individual weight of fishes, each fish was kept inside the respective saline water for an hour. Also, the lid of the chamber was closed tightly and carefully to avoid air bubble inside the chamber. All four sides of the glass tank were covered with an opaque screen to minimise visual disturbances to the experimental fishes. The initial and final oxygen content was measured using digital oxy-meter 330 (sensitivity $0.01 \mathrm{mg} \mathrm{O}_{2} \mathrm{mg} \mathrm{l}^{-1}$ ) (E Merck, Germany). The oxygen consumption rate was calculated as mg of oxygen consumed per $\mathrm{kg}$ of fish per hour.

Data analysis

The experimental results were subjected to one-way ANOVA using Statistical Package, SPSS version 11. For growth analysis, two-way ANOVA was conducted taking into consideration of weight gain in different salinities and monthly weight gain. Duncan's multiple range test (DMRT) was carried out for post hoc comparison of means at $5 \%$ probability level. 


\section{Results and discussion}

Acute toxicity is a reliable and important method for understanding the toxic effects of physiological stressors like salinity in a biological system. Median lethal concentration $\left(\mathrm{LC}_{50}\right)$ for $96 \mathrm{~h}$ is the most widely accepted assay for estimating acute toxicity of a particular substance. In the present study, data pertaining to effect of salinity on L. rohita are presented in Table 1 . The $\mathrm{LC}_{50}$ was calculated from probit analysis (Fig. 1) and found to be 9.60 and $7.72 \%$ corresponding to 48 and $96 \mathrm{~h}$ of exposure.

From the resutls it was observed that, the $\mathrm{LC}_{50}$ of salinity stress decreased with increase in the time of exposure. Similar to the present study, Ghosh et al. (1973) reported that Catla catla and L. rohita fry and fingerlings tolerated $8 \%$ salinity without mortality, but survivability gradually decreased with increase in salinity. In another study, Devika et al. (2003) reported that, L. rohita survived in waters up to $8 \%$ salinity and beyond this, the fish showed signs of stress and mortality.

Based on the information received from salinity tolerance test, a sublethal study was initiated to record

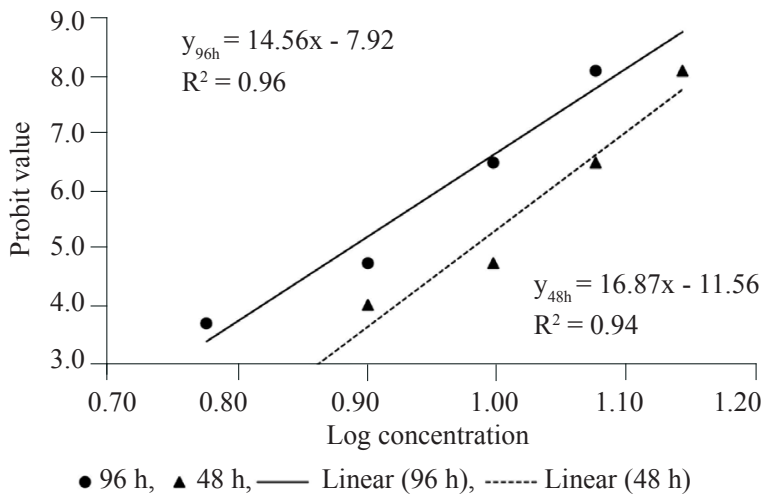

Fig. 1. Probit analysis for estimation of median lethal concentration of $L$. rohita exposed to various salinity levels for $96 \mathrm{~h}$ the impact of long term exposure of salinity on growth, mortality, tissue ascorbic acid levels and oxygen consumption in L. rohita. A 90 days' experiment was conducted and data pertaining to growth expressed in percentage weight gain of $L$. rohita is illustrated in Fig. 2 . From the figure it is clear that, average weight gain is maximum in control group followed by $2.5 \%$, then $3.5 \%$ and least in $4.5 \%$ at the end of 90 days of culture. Similarly, percentage weight gain was $32.2,6.88,4.02$ and $3.70 \%$ respectively at $0 ; 2.5 ; 3.5$ and $4.5 \%$ salinity levels (Fig. 2). Specific growth rate, daily growth rate and percentage growth rate (Fig. 3) also followed similar trend, highest in control followed by 2.5 and least in $4.5 \%$.

Growth rate of $L$. rohita showed decreasing trend with increasing salinity in the present study. Similar to the present study, decrease in specific growth rate and average daily gain have been recorded in $L$. rohita fingerling up to $8 \%$ salinity and the most preferred salinity for this species was found to be at 2\%o (Islam et al., 2014). Negative impact of salinity on growth have also been reported in L. rohita (Garg, 1996), Clarias batrachus (Sarma et al., 2013), Tilapia rendalli (Kang'ombe and

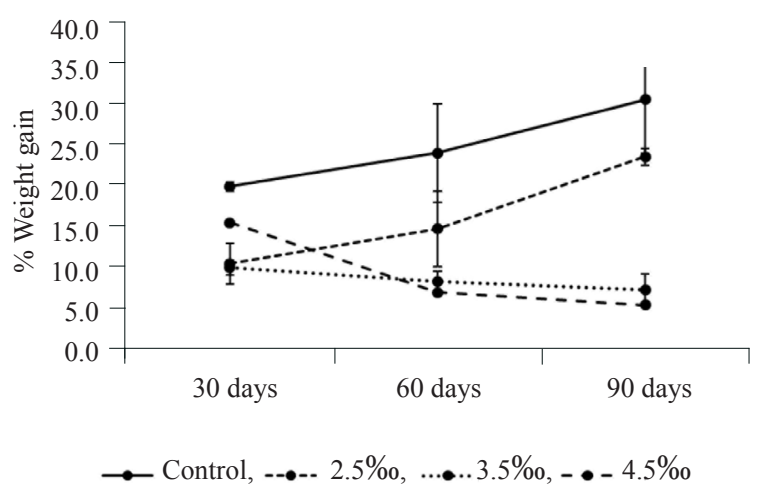

Fig. 2. Percentage weight gain of $L$. rohita exposed to different salinities for a period of 90 days

Table 1. Percentage mortality of $L$. rohita exposed to different salinity levels for a period of $96 \mathrm{~h}$

\begin{tabular}{|c|c|c|c|c|c|c|}
\hline \multirow{2}{*}{ Treatment $(\%$ ) } & \multirow{2}{*}{ No. of fishes } & \multicolumn{4}{|c|}{$\%$ Mortality } & \multirow{2}{*}{$\%$ Total mortality } \\
\hline & & $24 \mathrm{~h}$ & $48 \mathrm{~h}$ & $72 \mathrm{~h}$ & $96 \mathrm{~h}$ & \\
\hline 2,00 and 4,00 & 30 each & \multicolumn{4}{|c|}{ No mortality was recorded } & 0.00 \\
\hline 6.00 & 30 & 0.00 & 0.00 & 6.67 & 3.33 & 10.00 \\
\hline 8.00 & 30 & 0.00 & 16.67 & 10.00 & 13.33 & 40.00 \\
\hline 10.00 & 30 & 0.00 & 70.00 & 13.33 & 10.00 & 93.33 \\
\hline 12.00 & 30 & 76.67 & 16.67 & 3.33 & 3.33 & 100.00 \\
\hline 14.00 & 30 & 100.00 & 0.00 & 0.00 & 0.00 & 100.00 \\
\hline Exposure & $\mathrm{LC}_{50}$ & \multicolumn{3}{|c|}{ Confidence level } & \multicolumn{2}{|c|}{ Correlation coefficient (r) } \\
\hline $48 \mathrm{~h}$ & $9.60 \%$ & \multicolumn{3}{|c|}{$9.27-9.93 \%$} & \multicolumn{2}{|l|}{0.97} \\
\hline $96 \mathrm{~h}$ & $7.72 \%$ & \multicolumn{3}{|c|}{$7.41-8.03 \%$} & \multicolumn{2}{|l|}{0.98} \\
\hline
\end{tabular}




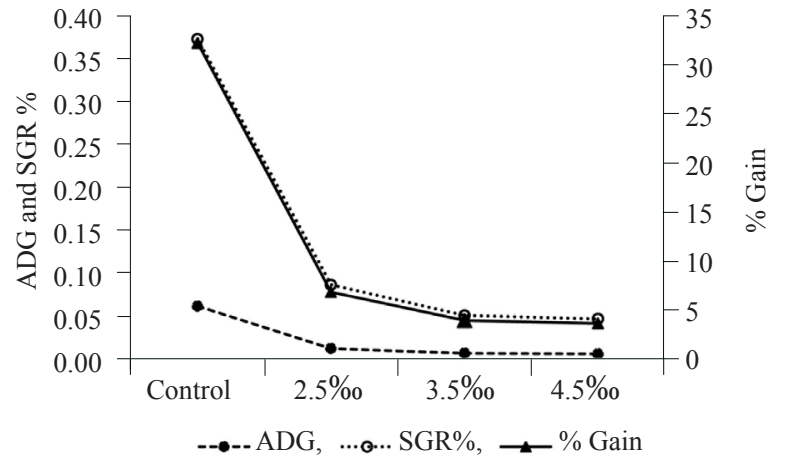

Fig. 3. Average daily gain (ADG), specific growth rate percentage (SGR\%) and percentage gain in weight (\% gain) of L. rohita exposed to different salinities for a period of 90 days of rearing

Brown, 2008), Nile tilapia (Schofield et al., 2011) and in Cyprinus carpio fingerlings (Wang et al., 1996). Decrease in growth rate at higher salinity levels could be attributed to the energetic cost for ionic and osmotic regulation to changes in environmental salinity (Altinok and Grizzle, 2003), to the damage and disruption of both primary and secondary gill lamellae which is directly exposed to saline environment or due to alterations in the metabolism which results from osmotic disturbances in fish.

In the present study, survival rate of L. rohita was also affected at higher salinities and duration of exposure (Fig. 4). Mortality was highest in fishes exposed to $4.5 \%$ salinity and least in control group (only one fish died) at the end of 90 days' exposure. No mortality was recorded in the first month of rearing. However, in a similar type of study on $L$ rohita, $100 \%$ survival rate of up to $6 \%$ salinity and $100 \%$ mortality beyond $10 \%$ salinity at 90 days of rearing have been reported (Islam et al., 2014). The difference in survival rate in contrast to the present study might be due to difference in size of fish used in the experiment, quality of feed used and experimental design adopted. Ghosh et al. (1973) reported that C. catla and L. rohita fry and fingerlings tolerated $8 \%$ salinity without mortality; however, survivability gradually decreased with increase in salinity. Low survival rates at higher salinity have been well documented in C. carpio (Mubarik et al., 2015) and C. batrachus (Sarma et al., 2013). In the present study, poor survival rate of L. rohita at higher salinity could be attributed to combined effect of confinement stress (Kang'ombe and Brown, 2008), low protein feed given during rearing period, reduced food intake (De Boeck et al., 2000) in addition to increased salinity stress.

Antioxidant vitamin $\mathrm{C}$ is well known for its major anti-stress role (Azad et al., 2007; Misra et al., 2007; Norouzitallab et al., 2009). In the present study, at the end of 90 days' culture period ascorbic acid level was estimated in brain, liver and muscle tissues and it was found that ascorbic acid level was significantly reduced $(p<0.05)$ in response to increase in salinity in brain, liver and muscle tissues (Fig. 5).

Ascorbic acid level was reduced by $11.0,38.5$ and $46.5 \%$ in brain; by $24.2,38.0$ and $36.4 \%$ in liver and $44.8,55.6$ and $53.8 \%$ in muscle tissue when exposed to $2.5,3.5$ and $4.5 \%$ salinity respectively. It appears that muscle is the most affected tissue followed by liver and brain. Similar results of decreasing ascorbic acid concentration in different organs with increasing salinity were also reported in case of $C$. batrachus when exposed to salinity and was attributed to stress mitigation effect of vitamin C (Sarma et al., 2013) or a defensive reaction of fish to combat stress (Madhuban and Kaviraj, 2009). In the present study, the reduction in ascorbic acid level might be due to high rate of utilisation of vitamin $\mathrm{C}$ at higher salinity levels. Vitamin C might have been used up for detoxification process (Mauck et al., 1978) or for preventing peroxidation of cells (Winston and Diguilo,

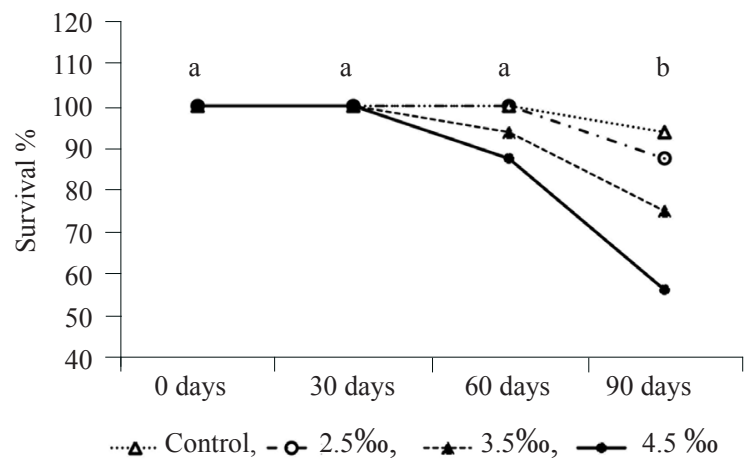

Fig. 4. Survival percentage of $L$. rohita exposed to different salinities for a period of 90 days of rearing

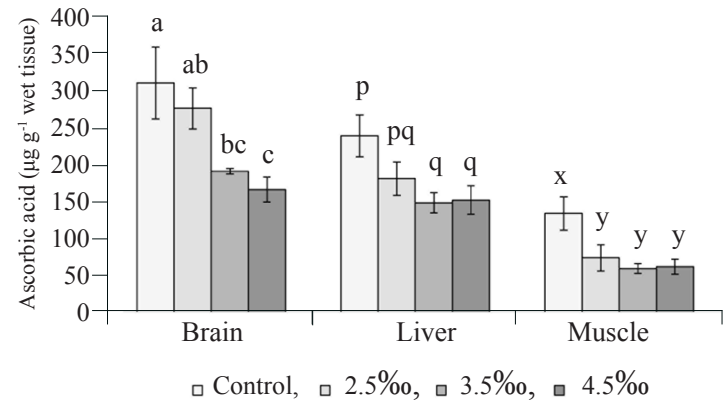

Fig. 5. Ascorbic acid level in different tissues of L. rohita exposed to different salinities at the end of 90 days of rearing. Data are expressed as mean $\pm S E, n=4$. Bars with different alphabets ( $\mathrm{a}, \mathrm{b}$ and $\mathrm{c}$ for brain, $\mathrm{p}$ and $\mathrm{q}$ for liver, $\mathrm{x}$ and $\mathrm{y}$ for muscle) differ significantly $(\mathrm{p}<0.05)$. 
1991), which in turn might have caused a functional reduction in vitamin $\mathrm{C}$ content in different tissues causing possible cell injury. Reduction of vitamin $\mathrm{C}$ in fish due to pesticides exposure has already been reported (Madhuban and Kaviraj, 2009; Sarma et al., 2009).

In the present study, rate of oxygen consumption was also estimated to record if there is any change in the consumption rate when exposed to high salinity. Data pertaining to oxygen consumption of $L$. rohita exposed to different salinities is depicted in Fig. 6. It was found that oxygen consumption was significantly affected $(p<0.05)$ with increase in salinity. The experiment was carried out in the laboratory within ambient water temperature of $28-30^{\circ} \mathrm{C}$. Maximum oxygen consumption was recorded at $2.5 \%$ beyond which oxygen consumption decreased and lowest value was recorded at $4.5 \%$. Metabolism is a physiological process reflecting the energy expenditure of living organisms (Sarma et al., 2009). The metabolic rate of fish is usually indirectly measured as their rate of oxygen consumption (Kutty, 1981). In the present investigation, the rate of oxygen consumption in fish was significantly altered with increasing salinity. Oxygen consumption rate was increased above $0 \%$ and reached highest at $2.5 \%$, afterwards progressively decreased and reached lowest at $4.5 \%$. Similarly, there was behavioural alteration also. Fishes were very active, quickly responding to external stimuli at $2.5 \%$ while very lethargic and slow in response to external stimuli at $4.5 \%$. It is well known that with increase in temperature, oxygen consumption rate is increased (Das et al., 2005; Brahmane et al., 2014), however, there is paucity of information on direct effect of salinity alone on rate of oxygen consumption of freshwater species. Zheng et al. (2008) recorded lower oxygen consumption rate at $31 \%$ compared to $16 \%$ o on Miichthys miiuy. While in another study on oxygen consumption rate of Dicentrarchus labrax fingerlings, only slight variation was recorded between 3 and $45 \%$ at $20^{\circ} \mathrm{C}$ which was attributed to strong euryhaline nature of the species (Barnabe, 1990; Dalla et al., 1998).

The alterations in oxygen consumption in fishes at different salinities could be due to differences in energy required for osmoregulation or from changes in the spontaneous activity level of fish and changes in the routine metabolic rate (De Boeck et al., 2000). In the present study, oxygen consumption rate was lowest at $4.5 \%$ which could be attributed to energy conservation strategy adopted by the species to salinity mediated stress.

Based on the results of the present investigation, it can be summarised that, long term exposure to salinity can have significant impact in growth and physiology of $L$. rohita. The study clearly indicated that $L$. rohita can

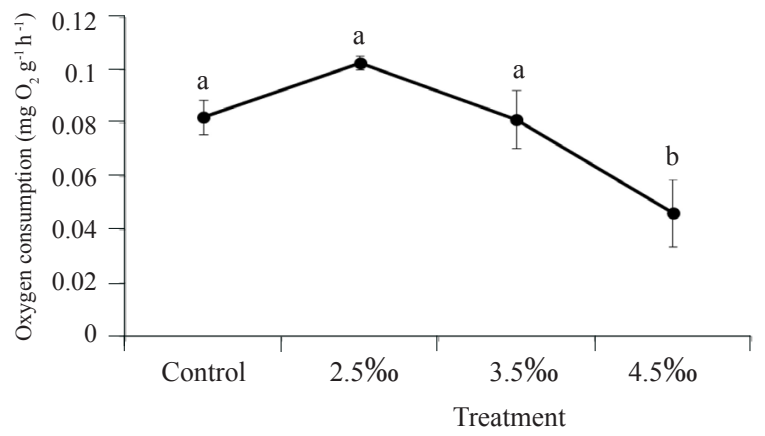

Fig. 6. Rate of oxygen consumption of L. rohita exposed to different salinity levels. Data are expressed as mean \pm SE, $\mathrm{n}=3$. Different alphabets against different salinities differ significantly $(\mathrm{p}<0.05)$

tolerate up to $2.5 \%$ salinity without any adverse effect on metabolism and growth. However, at higher salinity levels (3.5 and 4.5\%), growth, survival, tissue ascorbic acid levels as well as oxygen consumption were severely affected. Hence, it is not desirable to culture L. rohita at higher saline conditions. Being one of the most widely cultured freshwater species in India, studies to assess the impact of salinity on different life stages of this species is essential before introducing this species in low saline waters for farming purpose.

\section{Acknowledgments}

The authors are grateful to the Director, ICAR Research Complex for Eastern Region, Patna and NAIP, ICAR, New Delhi for providing facilities to carry out the present investigation.

\section{References}

Akhtar, M. S., Pal, A. K., Sahu, N. P., Ciji, A., Meena, D. K. and Das, P. 2013. Physiological responses of dietary tryptophan fed Labeo rohita to temperature and salinity stress. J. Anim. Physiol. Anim. Nutr., 97: 1075-1083. doi: 10.1111/ jpn.12017.

Altinok, I. and Grizzle, J. 2003. Effects of low salinities on oxygen consumption of selected euryhaline and stenohaline freshwater fish. J. World. Aquac. Soc., 34(1): 113-117. DOI: 10.1111/j.1749-7345.2003.tb00046.x.

APHA 1998. Standard methods for the examination of water and wastewater, $20^{\text {th }}$ edn. In: Clesceri, L. S., Greenberg, A. E. and Eaton, A. D. (Ed.), American Public Health Association, American Water Works Association, Water Environment Federation, Washington DC, USA. $1979 \mathrm{pp}$.

Azad, I. S., Dayal, J. S., Poornima, M. and Ali, S. A. 2007. Supra dietary levels of vitamins $\mathrm{C}$ and $\mathrm{E}$ enhance antibody production and immune memory in juvenile milk fish, Chanos chanos to formalin-killed Vibrio vulnificus. 
Fish Shellfish Immunol., 23: 154-163. doi: 10.1016/j.fsi. 2006.09.014.

Barnabe, G. 1990. Rearing bass and gilthead bream. In: Barnabe, G. (Ed.), Aquaculture, vol. 2. Ellis Horwood, New York, USA, p. 647-686.

Brahmane, M. P., Krishnan, K. K., Sarkar, B., Sajjanar, B., Kumar, S., Nkhawa, A. D. and Minhas, P. S. 2014. Growth, thermal tolerance and oxygen consumption in rohu, Labeo rohita early fry acclimated to four temperatures. Afr. $J$. Agric. Res., 9(9): 854-858.

Dalla Via, J. V., Villain, P. and Gasteiger, E. 1998. Oxygen consumption in seabass fingerling Dicentrarchus labrax exposed to acute salinity and temperature changes: metabolic basis for maximum stocking density estimations. Aquaculture, 169: 303-313. DOI: 10.1016/s0044-8486(98) 00375-5.

Das, T., Pal, A. K., Chakraborty, S. K., Manush, S. M., Sahu, N. P. and Mukherjee, S. C. 2005. Thermal tolerance, growth and oxygen consumption of Labeo rohita fry (Hamilton, 1822) acclimated to four temperatures. J. Therm. Biol., 30: 378-383.

De Boeck, Vlaminck, A. G., Van Der Linden, A. and Blust, R. 2000. The energy metabolism of common carp (Cyprinus carpio) when exposed to salt stress: an increase in energy expenditure or effects of starvation. Physiol. Biochem. Zool., 73(1): 102-111. doi: 10.1086/316717.

Debnath, D., Pal, A. K., Sahu, N. P., Baruah, K., Yengkokpam, S., Das, T. and Manush, S. M. 2006. Thermal tolerance and metabolic activity of yellowtail catfish Pangasius pangasius (Hamilton) advanced fingerlings with emphasis on their culture potential. Aquaculture, 258: 606-610. doi:10.1016/j.aquaculture.2006.04.037.

Devika, P., Susheela, J., Mohan, M. V. and Aneykutty, J. 2003. Effect of salinity on growth and survival of rohu, L. rohita (Ham.) under laboratory and field conditions Fish. Technol., 40(2): 91-94.

Garg, S. K. 1996. Brackishwater carp culture in potentially waterlogged areas using animal wastes as pond fertilisers. Aquac. Int., 4: 143-155.

Ghosh, A. N., Ghosh, S. R. and Sarkar, N. N. 1973. On the salinity tolerance of fry and fingerlings of Indian major carps. J. Inland Fish. Soc. India, 5: 215-217.

Islam, M., Ahsan, D. A., Mandal, S. C. and Hossain, A. 2014. Effects of salinity changes on growth performance and survival of rohu fingerlings, Labeo rohita (Hamilton 1822). Coast. Dev., 17(1): 1-6. DOI: 10.4172/1410-5217.1000379.

Kang'ombe, J. and Brown, J. A. 2008. Effect of salinity on growth, feed utilisation, and survival of Tilapia rendalli under laboratory conditions. J. Appl. Aquac., 20(4): 256-271. https://doi.org/10.1080/10454430802498229.
Kutty, M. N. 1981. Energy metabolism in mullet. In: Oren O. H. (Ed.), Aquaculture of grey mullets. Cambridge University Press, London, UK, p. 219-253

Lymbery, A., Starcevich, M. and Doupe, R. 2007. Managing environmental impacts in inland saline aquaculture: A case study for trout production from saline groundwater in Western Australia. A report for the Rural Industries Research and Development Corporation, Australia, 68 pp.

Madhuban, B. and Kaviraj, A. 2009. Toxicity of the pyrethroid pesticide fenvalerate to freshwater catfish Clarias gariepinus: Lethality, biochemical effects and role of dietary ascorbic acid. J. Environ. Sci. Health. B., 44(B): 578-583. DOI: 10.1080/03601230903000602.

Mandal, A. K. and Sharma, R. C. 2006. Computerized database of salt affected soils for agro-climatic regions in the IndoGangetic plain of India using GIS. Geocarto Int., 21(2): 47-57. https://doi.org/10.1080/10106040608542383.

Mauck, W. L., Mehrle, P. M. and Mayer, F. L. 1978. Effect of polychlorinated biphenyl Arochor ${ }^{\circledR} 1254$ on growth, survival and bone development in brook trout, Salvelinus fontinalis. J. Fish. Res. Board Can., 35: 1084-1088.

McDowall, S., Awal, S. and Christie, A. 2016. Investigation into the potential use of inland saline groundwater for the production of live feeds for commercial aquaculture purposes. J. Aquac. Mar. Biol., 4(1): 00071. DOI: 10.15406/ jamb.2016.04.00071.

Misra, C. K., Das, B. K., Mukherjee, S. C. and Pradhan, J. 2007. Effects of dietary vitamin $\mathrm{C}$ on immunity, growth and survival of Indian major carp Labeo rohita fingerlings. Aquac. Nutr., 13: 35-44. https://doi.org/10.1111/j.13652095.2007.00451.x.

Mubarik, M. S., Hussain, A. I. S. M., Farhat, F., Samiullah, K., Yaqub, S., Ahmad, S., Feroz, K., Khan, M. T., Nazli, S. and Ahmad, B. 2015. Survival, growth and body composition of Cyprinus carpio under different levels of temperature and salinity. Int. J. Biol. Sci., 6(10): 132-141.

Norouzitallab, P., Farhangi, M., Babapour, M., Rahimi, R., Sinha, A. K. and Baruah, K. 2009. Comparing the efficacy of dietary $\alpha$-tocopherol with that of DL- $\alpha$-tocopheryl acetate, both either alone or in combination with ascorbic acid, on growth and stress resistance of angelfish Pterophylum scalare juveniles. Aquac. Int., 17(3): 207-216. DOI: $10.1007 / \mathrm{s} 10499-008-9192-8$.

Reish, D. L. and Oshida, P. A. 1987. Manual of method in aquatic environment research, Part 10, Short term static bioassay. FAO Fisheries Technical Paper 247. Food and Agriculture Organisation, Rome, Italy, p. 1-62.

Roe, J. H. and Keuther, C. A. 1943. The determinations of ascorbic acid in whole blood and urine through the 2,4-dinitrophenylhydrazine (DNPH) derivative of dehydroascorbic acid. J. Biol. Chem., 147: 399-407.

Sahoo, L., Patel, A., Sahu, B. P., Mitra, S., Meher, P. K., Mahapatra, K. D., Dash, S. K., Jayasankar, P. and Das, P. 
2015. Preliminary genetic linkage map of Indian major carp, Labeo rohita (Hamilton 1822) based on microsatellite markers. J. Genet., 94: 271-277. doi: 10.1007/s12041-0150528-7.

Sahoo, S. K., Giri, S. S., Maharathi, C. and Sadhu, A. K. 2003. Effect of salinity on survival, feed intake and growth of Clarias batrachus (Linn.) fingerlings. Indian J. Fish., 50(1): 119-123.

Sarma, K., Pal, A. K., Sahu, N. P., Ayyappan, S. and Baruah, K. 2009. Dietary high protein and vitamin C mitigates endosulfan toxicity in Channa punctatus. Sci. Total Environ., 407(12): 3668-3673. doi: 10.1016/j.scitotenv. 2009.02.031.

Sarma, K., Prabakaran, K., Krishnan, P., Grinson, G. A. and Anand, K. 2013. Response of a freshwater air-breathing fish, Clarias batrachus to salinity stress: an experimental case for their farming in brackishwater areas in Andaman, India. Aquac. Int., 21(1): 183-196.
Schofield,P. J.,Peterson, M. S.,Lowe, M.R., Brown-Peterson, N. J. and Slack, W. T. 2011. Survival, growth and reproduction of non-indigenous Nile tilapia, Oreochromis niloticus (Linnaeus 1758) I. Physiological capabilities in various temperatures and salinities. Mar. Freshw. Res., 62: 439-449.

Wang, Ji-Qiao., Huanliang Lui, Hongyu Po and Lina Fan 1996. Influence of salinity on food consumption, growth and energy conversion efficiency of common carp (Cyprinus carpio) fingerlings. Aquaculture, 148: 115-124.

Winston, G. and Diguilo, R. 1991. Pro-oxidant and anti-oxidant mechanisms in aquatic organisms. Aquat. Toxicol., 19: 137-191.

Zheng, Z., Jin, C., Li, M., Bai, P. and Dong, S. 2008. Effects of temperature and salinity on oxygen consumption and ammonia excretion of juvenile miiuy croaker, Miichthys miiuy (Basilewsky). Aquac. Int., 16: 581-589. 